\title{
Pronóstico de caudales medios mensuales del rio caplina, aplicando redes neuronales artificiales (rna) y modelo autorregresivo periódico de primer orden par (1)
}

\section{Forecast for mean monthly discharge of the caplina river, by applying artificial neural network (rna) and periodic Autoregressive model par (1)}

\author{
Pino Vargas Edwin ${ }^{1}$, Siña Espinoza Luis ${ }^{2}$, Román Arce Carmen ${ }^{3}$
}

\author{
${ }^{1}$ Programa de Doctorado en Recursos Hídricos / U.N.Agraria La Molina, Lima Perú, epino68@hotmail.com \\ 2 Universidad Nacional Jorge Basadre G. Tacna, lucho_sies@hotmail.com \\ ${ }^{3}$ Universidad Nacional Jorge Basadre G. Tacna, romañ carmen@hotmail.com
}

\section{RESUMEN}

El rio Caplina es el principal tributario de la cuenca hidrográfica del mismo nombre; tiene una extensión de 4 $239,09 \mathrm{~km} 2$, esto hace que sea una de las principales fuentes de abastecimiento de agua para distintos usos en la ciudad de Tacna. Por esta razón diversas entidades se han interesado en conocer la disponibilidad hídrica actual y futura del rio Caplina, ya que conocer dichos valores es de fundamental importancia para el planeamiento y manejo de los sistemas de recursos hídricos. Los modelos estocásticos han sido durante largo tiempo, la alternativa más común en la predicción de caudales. Actualmente, las herramientas de computación inteligente como las redes neuronales artificiales, especialmente las redes multi-capas con algoritmo de retro-propagación. En este contexto, la actual investigación centro sus esfuerzos en la aplicación de las redes neuronales a la predicción de los caudales medios mensuales del río Caplina-Estación Bocatoma Calientes, desarrollo de modelos de redes neuronales a partir de datos de caudales, precipitación y evaporación, así como la evaluación de la capacidad de desempeño frente a modelos estocásticos. De esta manera, se desarrollaron 10 modelos de redes neuronales artificiales con distintas arquitecturas, cuyo entrenamiento se realizo con un primer subconjunto de datos correspondientes al periodo 1939 - 1999, y su validación con un segundo subconjunto de datos del periodo 2000 - 2006. Los modelos de redes neuronales artificiales mostraron comparativamente mejor desempeño en materia de predicción frente a un modelo autorregresivo periódico de primer orden PAR (1).

Descriptores: Cuenca Caplina, Redes Neuronales Artificiales, Series de Tiempo

\section{ABSTRACT}

Caplina river is the main tributary of the hydrographic basin of the same name, It has an extension of 4239,09 $\mathrm{km} 2$, because of this reason it is one of the principal sources of water supply for different uses in Tacna's city. For this reason diverse entities have been interested in knowing the water current and future availability of the river Caplina, because know the above mentioned values performs is the fundamental importance for the planning and managing of the systems of water resources. The stochastic models have been during long time, the most common alternative in the prediction of flows. Nowadays, the tools of intelligent computation like the artificial neural networks, specially the networks you multi-geld with algorithm of retro-spread. In this context, the current investigation center his efforts on the application of the neural networks to the prediction of the average monthly flows of the river Caplina-station Bocatoma Calientes, model development of neural networks from information of flows, rainfall and evaporation, as well as the evaluation of the capacity of performance opposite to stochastic models. So, 10 models of artificial neural networks were developed with different architectures, which training was realize with the first subset of information corresponding to the period 1939 - 
1999 , and his validation with the second subset of information of the period $2000-2006$. The models of artificial neural networks showed comparatively better performance as for prediction opposite to a periodic autoregressive model of the first order PAR (1).

Keywords: Caplina Basin, artificial neural networks, Series of Time

\section{INTRODUCCIÓN}

La disponibilidad de agua en cantidad y calidad insuficientes para la atención de los diversos usos y usuarios es sin duda uno de los más importantes problemas a ser enfrentados en el manejo de los recursos hídricos en una cuenca hidrográfica. Generalmente, la asignación de agua para la atención de las demandas está condicionada por la disponibilidad de agua en el espacio y tiempo, por lo que se hace necesario conocer con aproximación la disponibilidad presente y futura del recurso hídrico, con la finalidad de formular propuestas actuales y futuras para una adecuada gestión de los recursos hídricos.

Dada la importancia de la previsión de caudales, durante las últimas décadas se han propuesto gran variedad de modelos, entre estos tenemos a los modelos de alisamiento exponencial, modelos de regresión lineal y no lineal, modelos de series de tiempo estocásticas y muy recientemente se han introducido nuevos modelos de previsión, que manejan de una manera eficiente la aleatoriedad de los caudales y presentan una fácil adaptabilidad a nuevos datos, sin la necesidad de incurrir en laboriosas formulaciones matemáticas. Entre estos modelos se incluyen las técnicas de inteligencia artificial, las que comprenden las técnicas de Redes Neuronales, Sistemas Fuzzy, Sistemas Neuro-Fuzzy (Zuniga y Jordan, 2005), Teoría Nebulosa, Sistemas Multi-Agentes, entre otros.

\section{METODOLOGÍA}

Para el modelamiento con redes neuronales artificiales de la serie de caudales medios mensuales del río Caplina, el conjunto de datos de caudales medios mensuales se dividió en dos subconjuntos, el primero consta de 60 años de registros (1939 - 1999), utilizado para el entrenamiento del modelo y el segundo que comprende un total de 7 años $(2000$ - 2006) fue utilizado para fines de validación del modelo (predicción). Para dicho fin se utilizó el programa AlyudaNeurolntelligence $2.4 \quad$ (evaluación), desarrollado por ALYUDA ResearchCompany, dicho programa permite la construcción, entrenamiento, prueba y validación de modelos de redes neuronales artificiales.
A continuación se describe el procedimiento seguido:

1. Formulación de modelos de redes neuronales artificiales.

De acuerdo a los objetivos planteados en esta investigación, se han formulado 10 modelos de redes neuronales artificiales, cada uno con un conjunto propio de variables de entrada (caudales, precipitación y evaporación) y siempre con la misma variable de salida (Caudal).

Tabla 1. Modelos Propuestos

\begin{tabular}{|c|l|}
\hline $\mathrm{N}^{\circ}$ & Modelos \\
\hline 1 & $Q_{t}=f\left(Q_{t-1}\right)$ \\
2 & $Q_{t}=f\left(Q_{t-1}, Q_{t-2}\right)$ \\
3 & $Q_{t}=f\left(Q_{t-1}, Q_{t-2}, Q_{t-3}\right)$ \\
4 & $Q_{t}=f\left(Q_{t-1}, Q_{t-2}, Q_{t-3}, Q_{t-4}, Q_{t-5}, Q_{t-6}\right)$ \\
5 & $Q_{t}=f\left(P_{t}, E_{t}\right)$ \\
6 & $Q_{t}=f\left(P_{t}, P_{t-1}, E_{t}, E_{t-1}\right)$ \\
7 & $Q_{t}=f\left(P_{t}, P_{t-1}, P_{t-2}, E_{t}, E_{t-1}, E_{t-2}\right)$ \\
8 & $Q_{t}=f\left(P_{t}, E_{t}, Q_{t-1}\right)$ \\
9 & $\left.Q_{t}\right)$ \\
10 & $Q_{t}=f\left(P_{t}, P_{t-1}, E_{t}, E_{t-1}, Q_{t-1}\right)$ \\
& $Q_{t}=f\left(P_{t}, P_{t-1}, P_{t-2}, E_{t}, E_{t-1}, E_{t-2}, Q_{t-1}, Q_{t-2}\right)$ \\
\hline
\end{tabular}

2. Determinación de la arquitectura y parámetros de los modelos de redes neuronales artificiales.

Para la selección adecuada del numero de capas y neuronas intermedias de la red, se utilizó un conjunto de arquitecturas candidatas y a través de la técnica de validación cruzada se estimaron los parámetros, verificando el desempeño de los modelos sobre el conjunto de validación, siendo elegido el modelo que presentó el mejor desempeño en relación al error cuadrático medio.

3. Fase de entrenamiento de los modelos de redes neuronales artificiales.

El proceso de entrenamiento de los modelos de redes neuronales artificiales se efectuó con el primer subconjunto de la serie de caudales medios mensuales del río Caplina, que comprende un total de 60 años de registro (1939 - 1999).

Este proceso consistió en evaluar distintas opciones de entrenamiento haciendo variar la cantidad de ciclos de cálculo al igual que la tasa de aprendizaje 
con el objetivo de minimizar el error en el pronóstico. Durante la fase de entrenamiento de la red, se determine iterativamente los pesos de las conexiones, Wji que conectan a las neuronas de entrada con las de la capa oculta y $W_{j}$ j para la transferencia entre la capa oculta y la de salida. A partir de los datos de entrada la red en cada iteración propaga una salida, a través de las neuronas que la componen, con los pesos y función de transferencia considerada, esta salida se compara con la real, obteniéndose así un error. El entrenamiento concluye cuando la red es capaz de reproducir las salidas conocidas para los parámetros de entrada, con un error mínimo arbitrario. La función de transferencia y activación utilizada fue del tipo sigmoidea.

4. Selección de los mejores modelos de redes neuronales artificiales

Como principal criterio de evaluación, la capacidad de desempeño y generalización a través de las estadísticas de validación de los modelos, tanto para la fase de entrenamiento, como para la de validación, se efectuó la selección de los mejores modelos.

\section{RESULTADOS Y DISCUSIÓN}

Los modelos seleccionados son:

- El modelo 4 es el que presenta mejor desempeño dentro de los 4 modelos que consideran como variables de entrada únicamente caudales medios mensuales.

- El modelo 7 es el que presenta mejor desempeño dentro de los 3 modelos que consideran como variables de entrada valores de precipitación y evaporación mensual.

- El modelo 10 es el que presenta mejor desempeño dentro de los 3 modelos que consideran como variables de entrada valores de precipitación, evaporación, y caudales medios mensuales.

Figura 1. Predicción de caudales con el modelo 4 (RNA)

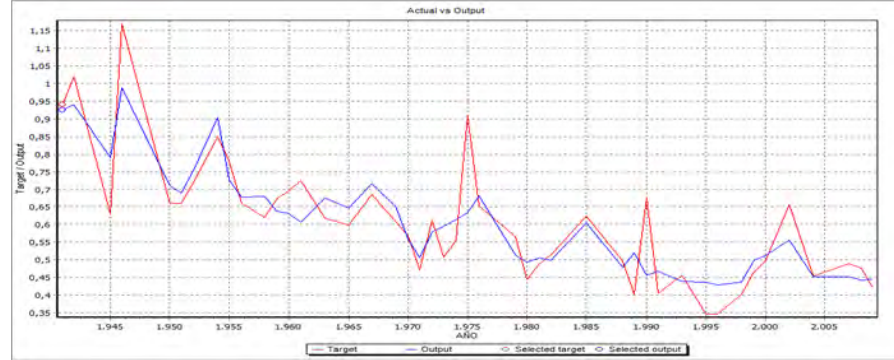

Figura 2. Predicción de caudales con el modelo 7 (RNA)

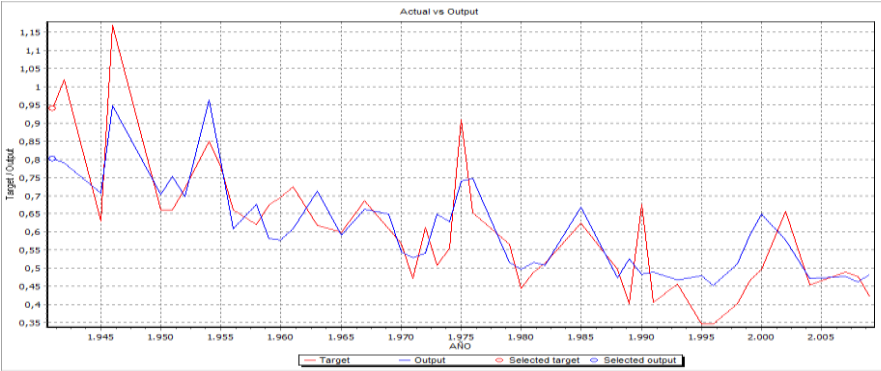

Figura 3. Predicción de caudales con el modelo 10 (RNA)

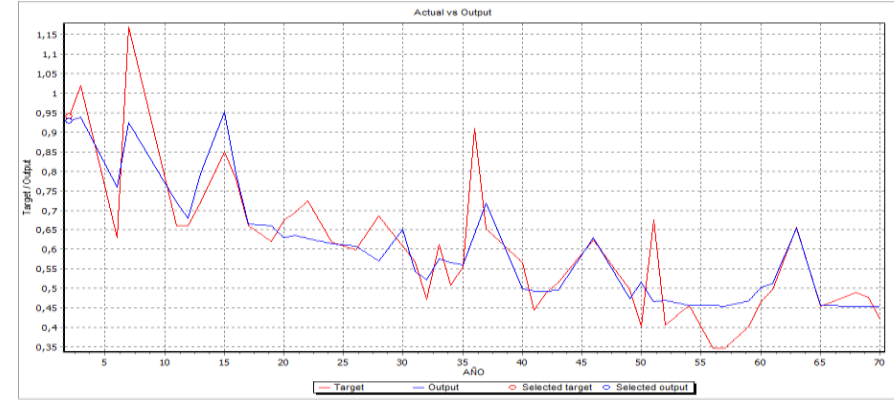

Se confirma la necesidad de utilizar modelos de redes neuronales artificiales en el modelamiento y pronostico de caudales medios mensuales, ya que se consiguió una mayor efectividad en los resultados

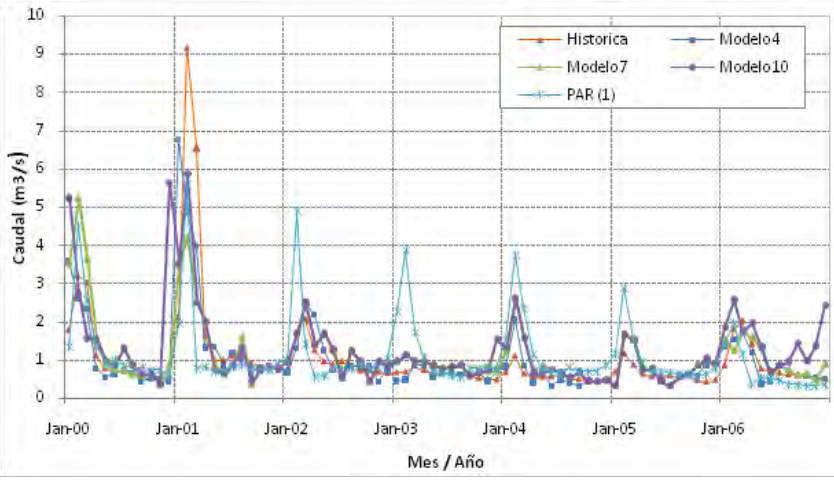

de predicción con valores muy cercanos a los reales, lo que confirma la robustez y grandes ventajas de la modelación inteligente, en comparación a un modelo de serie temporal estocástica PAR (1)

Figura 4. Comparación de modelos 


\section{CONCLUSIONES}

Las redes neuronales artificiales desde el punto de vista de predicción o pronostico de caudales mensuales, muestra un comportamiento excelente en términos de las estadísticas de los errores de predicción; mas aun cuando de manera comparó con un modelo autorregresivo periódico de primer orden - PAR (1), mostrando un grado superior de eficiencia en las predicciones realizadas, ya que presentan porcentajes de ajuste superiores al $80 \%$, en comparación al $62 \%$ que presenta el modelo de serie de tiempo estocástica. Dichos resultados son altamente promisorios y sugieren que el enfoque propuesto tiene mejores rendimientos que los modelos de series temporales estocásticas en términos de error de predicción, eficiencia y estimación de picos.

Se logro establecer y desarrollar modelos de redes neuronales de gran efectividad, a partir de datos de caudales, precipitación y evaporación, lo que demuestra la capacidad de los modelos de redes neuronales artificiales en la predicción de caudales medios mensuales a partir de este tipo de información.

Independientemente del conjunto de entradas utilizado, todos los modelos de redes neuronales mostraron un mejor desempeño en comparación al modelo PAR (1), sin embargo el modelo 4 $\left(Q_{-} t=f\left(Q_{-}(t-1), Q_{-}(\mathrm{t}-2), Q_{-}(\mathrm{t}-3), Q_{-}(\mathrm{t}-4), Q_{-}(\mathrm{t}-5), \mathrm{Q}_{-}(\mathrm{t}-6)\right.\right.$ )) es el que presenta mejor desempeño dentro de los modelos que consideran como variables de entrada únicamente caudales medios mensuales. El modelo $7\left(Q_{\mathrm{t}}=\mathrm{f}(\mathrm{P} t \mathrm{t}, \mathrm{P}(\mathrm{t}-1), \mathrm{P}(\mathrm{t}-2), \mathrm{E} \mathrm{t}, \mathrm{E}(\mathrm{t}-1), \mathrm{E}(\mathrm{t}-2))\right)$, es el que presenta mejor desempeño dentro de los modelos que consideran como variables de entrada valores de precipitación y evaporación mensual. El modelo $10 Q_{-} t=f\left(P \_t, P \_(t-1), P \_(t-2), E_{-} t, E_{-}(t-1)\right.$, E_( $t-$ 2), $Q_{-}(\mathrm{t}-1), \mathrm{Q}_{-}(\mathrm{t}-2) \overline{\text { ) }}$, es el que presenta mejor desempeño dentro de los 3 modelos que consideran como variables de entrada valores de precipitación, evaporación, y caudales medios mensuales.

\section{AGRADECIMIENTOS}

Agradecimiento especial al programa de post-grado en la Especialidad de Recursos Hídricos de la Universidad Nacional Agraria La Molina y la Escuela de Ingeniería Geológica-Geotecnia de la Universidad Nacional Jorge Basadre G. De Tacna.

\section{REFERENCIAS}

[1] ALEGRE, A. 2003. Simulación de redes neuronales artificiales: Una aplicación didáctica. Tesis Lic. Sistemas. Universidad Nacional del Nordeste. Corrientes, Argentina.

[2] DOLLING, O. 2001. Sistemas de apoyo a la gestión integral de cuencas hidrográficas. Tesis Dr. Universidad Nacional San Juan. Santiago, Chile.

[3] TOKAR, A; MARKUS, M. 2000. Precipitationrunoof modeling using artificial neural networks and conceptual models.

[4] LAQUI, W. 2008 Predicción de caudales mensuales del rio Huancané utilizando modelos de redes neuronales artificiales.

[5] DÖLLING, O. 2001 Utilización de Redes Neuronales Artificiales al Pronóstico de Caudales en Cuencas Nivales.

[6] ZUÑIGA, A; JORDÁN, C. 2005. Pronostico de caudales medios mensuales empleando sistemas neuro-fuzzy.

[7] Evolución y ordenamiento de los recursos hídricos en las cuencas de los ríos Caplina y Uchusuma, 2002.

E-mail: epino68@hotmail.com 